\title{
Fatores de risco, etiologia e aspectos clínicos da mastite em ovelhas de corte no Paraná ${ }^{1}$
}

\author{
Priscilla F.V. Pereira² ${ }^{2}$ Erika S. Stotzer ${ }^{3}$, Lucienne G. Pretto-Giordano ${ }^{4}$, Ernst \\ E. Müller ${ }^{5}$ e Júlio A.N. Lisbôa ${ }^{5 *}$
}

\begin{abstract}
Pereira P.F.V., Stotzer E.S., Pretto-Giordano L.G., Müller E.E. \& Lisbôa J.A.N. 2014. [Risk factors, etiology and clinical aspects of mastitis in meat ewes of Parana, Brazil.] Fatores de risco, etiologia e aspectos clínicos da mastite em ovelhas de corte no Paraná. Pesquisa Veterinária Brasileira 34(1):1-10. Departamento de Clínicas Veterinárias, Centro de Ciências Agrárias, Universidade Estadual de Londrina, Campus Universitário, Cx. Postal 6001, Londrina, PR 86051-990, Brazil. E-mail: janlisboa@uel.br

Mastits is infrequent in meat ewes. However Santa Ines ewes have a high incidence of this disease and it is severe and difficult to treat. The goal of this study was to characterize clinical, epidemiological and etiological aspects of clinical mastitis in meat ewes reared in the north of Parana, Brazil. Fifith four farms were visited from October 2009 to September 2010. The surveyed data included frequency, breeds of sheep affected, lamb mortality rates, main clinical signs, attempts and outcome of treatment, method and period of weaning and management features. Seventy ewes with clinical mastitis were fully examinated and samples of mammary secretion were asseptically taken for bacteriological culture. Mastitis was identified in 39 farms (72.3\%) as a relevant problem (mean frequency was $6,74 \%$ ). Chronic and acute mastitis were observed in $69 \%$ and $31 \%$ of the examinated ewes, respectively. In both cases, phlegmonous mastitis was the most prevalent form (65.5\%). Coagulase negative Staphylococccus (CNS) was the main isolated microorganism (54.5\%), followed by Staphylococcus aureus and Arcanobacterium pyogenes (11.5\%, each one). Mannheimia haemolytica was found in two cases. The risk factors for clinical mastitis were intensive management system and Santa Ines breed. Weaning after 120 days of lactation and isolation of affected ewes were associated with lower frequency of mastitis. Preventive measures recommended are daily cleaning of facilities and delayed weaning, mainly in Santa Ines flocks.
\end{abstract}

INDEX TERMS: Mastitis, intramammary infection, etiology, predisponents factors, ewes, Santa Inês breed, clinical signs.

\footnotetext{
${ }^{1}$ Recebido em 8 de agosto 2013.

Aceito para publicação em 27 de setembro de 2013.

${ }^{2}$ Doutoranda do Programa de Pós-Graduação em Ciência Animal, Universidade Estadual de Londrina (UEL), Rodovia Celso Garcia Cid, PR 445, km 380, Cx. Postal 6001, Londrina, PR 86051-990, Endereço particular: Rua Professor João Cândido 1350, apto 602, Centro, Londrina, PR 86010001, Brasil.

${ }^{3}$ Médica Veterinária graduada pela UEL. Endereço particular: Rua das Celósias 1249-W, Bairro Bandeirantes II, Lucas do Rio Verde, MT 78455000, Brasil.

${ }^{4}$ Departamento de Medicina Veterinária Preventiva, Centro de Ciências Agrárias (CCA), UEL, Londrina, PR.

${ }^{5}$ Departamento de Clínicas Veterinárias, CCA-UEL, Campus Universitário, Rodovia Celso Garcia Cid, PR 445, km 380, Cx. Postal 6001, Londrina, PR 86051-990.*Autor para correspondência: janlisboa@uel.br
}

RESUMO.- A mastite em ovelhas da raça Santa Inês apresenta-se como um problema de grande proporção e gravidade e é dificilmente tratada com sucesso. 0 objetivo deste estudo foi caracterizar aspectos clínicos, epidemiológicos e etiológicos da mastite clínica em ovelhas de corte criadas no norte do Paraná. 0 presente estudo foi realizado entre os meses de outubro de 2009 a setembro de 2010 envolvendo 54 rebanhos de ovinos de corte de diferentes raças. Durante as visitas às propriedades, um questionário foi preenchido com a finalidade de caracterizar o problema. Setenta ovelhas com mastite clínica foram examinadas e amostras de secreção láctea foram colhidas para exame microbiológico. A mastite foi considerada um problema relevante em 39 propriedades (72,3\%), com frequência 
média de 6,74\%. Casos crônicos e agudos de mastite foram observados em $69 \%$ e $31 \%$ das ovelhas examinadas, respectivamente. Em ambos os casos, a mastite flegmonosa foi a forma mais encontrada (65,5\% dos casos). 0 agente etiológico mais prevalente foi Staphylococcus coagulase negativo (54,5\%), seguido por $S$. aureus e A. pyogenes $(11,5 \%$ cada). Mannheimia haemolytica foi isolada em dois casos. Sistema de criação não extensivo e raça Santa Inês foram identificados como fatores de risco para o desenvolvimento de mastite clínica. Secagem das fêmeas após 120 dias de lactação e separação de fêmeas doentes do rebanho foram associadas com menor ocorrência da doença. Recomenda-se a limpeza adequada das instalações e a secagem mais tardia, principalmente em rebanhos Santa Inês.

TERMOS DE INDEXAÇÃO: Mastite, infecção intramamária, etiologia, fatores predisponentes, ovinos, Santa Inês, sinais clínicos.

\section{INTRODUÇÃO}

A ovinocultura de corte é uma atividade em ascensão em todo o Brasil e as expectativas para o mercado de carne ovina são promissoras. A região Sul possui 4.886 .541 ovinos, mais de $28 \%$ da população nacional, segundo dados do IBGE (Brasil 2010). Nesta região a exploração de ovinos é uma atividade tradicional e rentável, tanto para médio como para pequenos produtores. No ano de 2010 o estado do Paraná detinha 613.934 cabeças, um incremento de $26,5 \%$ em relação à população ovina registrada no último Censo Agropecuário realizado três anos antes. A produção de carne ovina também cresceu entre os anos de 2003 e 2007, com produções de 2.386 e 4.361 toneladas, respectivamente (Paraná 2008).

Apesar da evolução mencionada existem alguns fatores limitantes ao crescimento desta atividade. Dentre os fatores sanitários, uma das enfermidades que mais se destaca é a mastite, pois leva a prejuízo econômico significativo. A infecção intramamária causa queda na produção e na qualidade do leite, custos com assistência veterinária e medicamentos, queda no ganho de peso e morte dos cordeiros, morte de matrizes e é a principal causa do descarte precoce de ovelhas, pela perda de função da mama acometida (Jones \& Watkins 2000, Menzies \& Ramanoon 2001, Mendonça et al. 2005).

A mastite é uma enfermidade que acomete ovelhas em todo o mundo e os estudos são mais numerosos nos países onde estes animais são criados para a produção leiteira (Bergonier et al. 2003, Contreras et al. 2007). Recentemente, o número de trabalhos realizados a respeito dessa enfermidade no Brasil aumentou principalmente devido à grande utilização da raça Santa Inês em rebanhos de todo o país. Esta raça é oriunda do cruzamento das raças Bergamácia e Morada Nova, tendo como principais características a rusticidade, a capacidade de se reproduzir o ano inteiro e a produção leiteira (Sousa et al. 2005). Quando animais desta raça são criados em regiões de clima mais ameno e com maior disponibilidade de alimento ao longo do ano, é esperada produção leiteira ainda maior, o que pode levar ao aumento na incidência de mastite (Blagitz 2007).

Os trabalhos nacionais acompanham a expansão da raça Santa Inês nos rebanhos das diferentes regiões. A maior parte dos estudos sobre mastite ovina foi realizada no Nordeste (Coutinho et al. 2006, 2008, Oliveira 2006, 2007, Almeida 2007, Santos et al. 2007, Melo et al. 2008, Santos 2008, Guaraná et al. 2011) onde a raça Santa Inês se originou. 0 número de trabalhos vem crescendo também na região Sudeste (Domingues et al. 2006, Blagitz 2007, Blagitz et al. 2008, Nunes et al. 2008, Veríssimo et al 2010). A maioria destes estudos explorou aspectos de etiologia e sensibilidade aos antimicrobianos em ovelhas acometidas por mastite subclínica. A caracterização das manifestações clínicas e os aspectos epidemiológicos não foram bem explorados nas publicações nacionais.

Nos últimos anos ocorreu a introdução de animais Santa Inês nos rebanhos do Paraná, tradicionalmente compostos por ovinos lanados, com o intuito de se aumentar a rusticidade e a prolificidade. A ovinocultura paranaense é voltada para a produção de cordeiro precoce e possui manejo diferente da ovinocultura nordestina. Os relatos de ovelhas com quadros graves de mastite, de evolução aguda, com envolvimento difuso do parênquima e ausência de secreção de leite tornaram-se frequentes. Não existem estudos sobre a mastite em ovelhas no estado do Paraná e os fatores de risco envolvidos não são completamente conhecidos. 0 presente estudo teve como objetivo caracterizar aspectos clínicos, epidemiológicos e etiológicos da mastite em ovelhas de corte criadas na região norte do Paraná.

\section{MATERIAL E MÉTODOS}

O presente trabalho foi aprovado pelo Comitê de Ética e Experimentação Animal da Universidade Estadual de Londrina (CEEA/ UEL), registrado sob o número 98/09. Foi realizado em 54 rebanhos de ovinos de corte do estado do Paraná, entre os meses de outubro de 2009 e setembro de 2010. Os produtores cujas propriedades foram visitadas estavam organizados, durante o período do estudo, numa cooperativa com a finalidade de produção de carne de cordeiro precoce. As propriedades se localizavam em 29 municípios diferentes, pertencentes, principalmente, às mesorregiões norte central (40 propriedades) e norte pioneiro paranaense ( 9 propriedades). As cinco propriedades restantes localizavam-se em municípios de outras mesorregiões.

Na ocasião da visita às propriedades, um questionário foi preenchido com a finalidade de caracterizar o problema a partir das seguintes informações: ocorrência da doença nos 12 meses anteriores; ocorrência de recidivas; padrão de evolução da doença; período da lactação em que ocorre; principais sinais clínicos observados; sucessos ou insucessos nos tratamentos; manejo de secagem da ovelha e desmame do cordeiro; procedimentos preventivos implantados; mortalidade de cordeiros; manejo das instalações; manejo sanitário em geral; caracterização do rebanho quanto ao padrão racial; manejo nutricional e reprodutivo e ocorrência de outras enfermidades.

As propriedades foram classificadas em dois grupos a partir do histórico da enfermidade e das informações do questionário: propriedades nas quais a mastite estava presente, como problema sanitário relevante e causador de prejuízo econômico, e aquelas nas quais a doença não estava presente ou era insignificante. Os rebanhos foram agrupados conforme o predomínio de indivíduos de cada raça em três grupos: predomínio de animais Santa Inês, predomínio de animais mestiços Santa Inês (cruzamentos entre indivíduos da raça Santa Inês e outras raças com cobertura de lã) e predomínio de animais lanados (indivíduos das raças Suffolk, Texel, Ile de France ou seus cruzamentos). 
Setenta ovelhas acometidas por mastite clínica foram examinadas. Realizou-se o exame das glândulas mamárias acometidas ( $n=87)$ empregando-se inspeção e palpação, segundo critérios recomendados por Grunert (1993), para avaliação de aumento de volume e assimetria entre as glândulas e das características de consistência do parênquima mamário, como presença de nódulos, edema, endurecimento difuso ou não e fibrose. Quando havia secreção presente, a colheita foi efetuada para realização do teste da caneca telada e da cultura microbiológica. 0 exame da caneca telada foi interpretado levando em consideração as características macroscópicas do leite (cor, consistência e presença de grumos, pus e sangue).

A colheita de amostras de leite para cultivo e identificação bacteriana foi realizada segundo as recomendações preconizadas pelo National Mastitis Council (2004) para bovinos. As amostras de leite foram colhidas após prévia higienização dos tetos, descarte dos primeiros jatos de leite, limpeza com álcool a $70^{\circ} \mathrm{GL}$ e secagem com papel toalha. $\mathrm{O}$ leite foi acondicionado em tubos de vidro com tampa rosqueada, previamente esterilizados e transportados, sob refrigeração $\left(4-8^{\circ} \mathrm{C}\right)$, em caixa de material isotérmico com gelo reciclável. No laboratório as amostras foram semeadas em placas contendo meio ágar nutriente ${ }^{6}$ com $5 \%$ de sangue ovino e em placas contendo meio ágar MacConkey ${ }^{7}$. As placas foram incubadas a $37 \pm 1^{\circ} \mathrm{C}$, e as leituras realizadas 24,48 , 72 e 96 horas após. Os micro-organismos isolados foram identificados segundo características morfotintoriais, bioquímicas e de cultivo, conforme Carter \& Cole Junior (1990), Quinn et al. (1994) e National Mastitis Council (2004). Para o isolamento de Mycoplasma spp. foi empregado o ágar de Hayflick modificado e as placas foram incubadas a $38^{\circ} \mathrm{C}$ por até 10 dias em microaerofilia (Pretto et al. 2001).

Para cada uma das 87 mamas examinadas que apresentavam alteração, o processo infeccioso/inflamatório foi classificado de acordo com sua evolução em agudo ou crônico, e de acordo com suas características clínicas em abscedante, catarral, flegmonoso e gangrenoso, como descrito por Grunert (1993).

Realizou-se estudo descritivo das variáveis investigadas determinando a distribuição de frequências e média \pm desvio padrão, quando pertinente. Estudou-se a correlação entre o número de cordeiros mortos e o número de ovelhas com mastite no rebanho, por meio do teste de Pearson. Admitiu-se probabilidade de erro de 5\%. Para a análise dos fatores de risco consideraram-se somente as informações referentes às 39 propriedades nas quais a mastite estava presente como problema sanitário relevante, totalizando 4.879 ovelhas e 329 acometidas pela doença. A análise de fatores de risco foi efetuada em duas etapas: análise univariada, onde cada variável independente foi cruzada com a variável dependente (presença de mastite clínica), e multivariada. As variáveis que apresentaram associação com a ocorrência de mastite $(\mathrm{p} \leq 0,20)$ pelo teste do Qui-quadrado (Zar 1999) foram submetidas à análise multivariada, empregando-se a regressão logística múltipla (Hosmer \& Lemeshow 2000). O nível de significância adotado na análise múltipla foi de $5 \%$. As análises foram realizadas com o programa SPSS for Windowns versão 21.0.

\section{RESULTADOS E DISCUSSÃO}

Das 54 propriedades visitadas, a ovinocultura era a principal atividade em 26 propriedades (48\%). Nas outras propriedades a principal atividade era a agricultura, a bo-

\footnotetext{
${ }^{6}$ Agar Nutriente $\mathrm{n} \times 2$, Himedia ${ }^{\circledR}$, Biosystems Com. Imp. Exp. Produtos Lab. Ltda, Rua Amazonas Marcondes 336, Cabral, Curitiba, PR, Brasil.

${ }^{7}$ Meio Agar MacConkey, Himedia ${ }^{\circledR}$, Biosystems Com. Imp. Exp. Produtos Lab. Ltda, Rua Amazonas Marcondes 336, Cabral, Curitiba, PR, Brasil.
}

vinocultura de corte ou a avicultura, sendo a ovinocultura uma atividade secundária. A maioria dos produtores criava ovinos há mais de cinco anos, e o tempo de criação variou entre três e 30 anos $(8,66 \pm 6,12$ anos). 0 sistema de manejo semi-intensivo era utilizado em 39 propriedades $(72,3 \%)$, com os animais soltos em piquetes durante o dia e presos em apriscos durante a noite (Quadros 1 e 2).

0 tamanho dos rebanhos pesquisados variou consideravelmente $(187,52 \pm 143,41$ cabeças $)$, com o maior rebanho composto por 596 animais e o menor rebanho por 38 animais. 0 número de matrizes nos rebanhos variou de 25 a 350, com média de $118( \pm 87,1)$ ovelhas por rebanho, totalizando 6.370 matrizes. Dessas, 1.432 eram da raça Santa Inês, 2.127 eram mestiças Santa Inês e 2.811 eram de raças lanadas. Dezoito rebanhos eram predominantemente compostos por animais Santa Inês, 13 rebanhos por mestiços Santa Inês e 23 por indivíduos lanados.

A verminose foi apontada pelos produtores como a principal enfermidade responsável por prejuízo econômico em 37 propriedades (68,5\%). A mastite foi apontada como o principal problema sanitário em cinco propriedades $(9,3 \%)$, seguida por linfadenite caseosa em quatro propriedades $(7,4 \%)$ e ceratoconjuntivite infecciosa, podridão dos cascos, ectima contagioso e morte súbita sem causa definida em duas propriedades cada uma $(3,7 \%)$. A assistência veterinária era regular em apenas 15 (27,8\%) propriedades. A principal queixa entre 60 criadores de ovinos Santa Inês em Sergipe foi a mastite, seguida da verminose, linfadenite caseosa e as pododermatites (Almeida 2007).

Com base no histórico da enfermidade no rebanho, a mastite foi considerada problema sanitário relevante, levando a prejuízo econômico significativo e presente de maneira frequente nas matrizes em 39 propriedades $(72,3 \%)$, apresentadas no Quadro 1. Nas 15 propriedades $(27,7 \%)$ restantes, a mastite não foi considerada problema sanitário significativo, ocorrendo esporadicamente e com menos de $2 \%$ de fêmeas acometidas nos últimos 12 meses (Quadro 2).

Nas propriedades em que a doença era relevante, a frequência de mastite clínica, conforme histórico dos doze últimos meses, variou entre 2 e $30 \%$, sendo $6,74 \%$ a frequência média. Este resultado está de acordo com as observações de Santos (2008) em pesquisa realizada na Paraíba, onde foram encontradas frequências de 5 a 20\% nos rebanhos, com frequência média de 10,78\%. Oliveira (2007) encontrou $15,5 \%$ de matrizes Santa Inês com mastite clínica em Pernambuco. Veríssimo et al. (2010) observaram frequência de $24,5 \%$ de mastite clínica em um rebanho no estado de São Paulo. Silva et al. (2010), no Pará, encontraram frequência de apenas 5,9\% de mastite clínica. A incidência anual de mastite clínica observada nos rebanhos leiteiros da Europa varia de 1 a 15\%, com média de 5\% (Winter 2001, Contreras et al. 2007). Para a mastite subclínica, por outro lado, a prevalência média estimada nos rebanhos leiteiros europeus varia de 20 a 30\% (Bergonier \& Berthelot 2003), o que se assemelha às frequências observadas nas ovelhas de corte da raça Santa Inês criadas no Brasil (Coutinho et al. 2006, Domingues et al. 2006, Guaraná et al. 2011). 
Quadro 1. Informações sobre o plantel, frequência da doença e manejo das propriedades $(n=39)$ onde a mastite era um problema sanitário nas ovelhas de rebanhos de corte criados na região norte do Paraná

\begin{tabular}{|c|c|c|c|c|c|c|c|}
\hline ID $^{\mathrm{a}}$ & Raça $^{c}$ & Município & $\begin{array}{l}\text { Tipo de } \\
\text { manejo }^{d}\end{array}$ & $\begin{array}{l}\text { Total de } \\
\text { ovelhas }\end{array}$ & $\begin{array}{c}\text { Frequência } \\
(\%)^{\mathrm{e}}\end{array}$ & $\begin{array}{l}\text { Ovelhas } \\
\text { curadas }^{\text {e }}\end{array}$ & $\begin{array}{c}\text { Ovelhas des- } \\
\text { cartadas }^{\mathrm{e}}\end{array}$ \\
\hline $1^{\mathrm{b}}$ & $\mathrm{S}^{\text {ta }}$ Inês & Londrina & SI & 40 & 30 & 0 & 2 \\
\hline $3^{\mathrm{b}}$ & 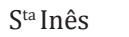 & Rolândia & SI & 100 & 18 & 0 & 6 \\
\hline $17^{\mathrm{b}}$ & $\mathrm{S}^{\text {ta }}$ Inês & Ibiporã & SI & 104 & 9 & 0 & 6 \\
\hline $18^{\mathrm{b}}$ & St $t^{\mathrm{a}}$ Inês & Jaguapitã & SI & 99 & 14 & 0 & 0 \\
\hline $24^{\mathrm{b}}$ & S ${ }^{\text {ta }}$ Inês & Bandeirantes & I & 50 & 6 & 1 & 2 \\
\hline $25 b$ & $\mathrm{~S}^{\text {ta }}$ Inês & Bandeirantes & I & 60 & 10 & 1 & 0 \\
\hline 26 & $\mathrm{~S}^{\text {ta }}$ Inês & Sertanópolis & I & 65 & 21 & 0 & 14 \\
\hline $27^{\mathrm{b}}$ & $\mathrm{S}^{\text {ta }}$ Inês & Rancho Alegre & SI & 60 & 5 & 0 & 0 \\
\hline $30^{\mathrm{b}}$ & $\mathrm{S}^{\text {ta }}$ Inês & Bela Vista & SI & 30 & 13 & 0 & 2 \\
\hline $31^{\mathrm{b}}$ & $\mathrm{S}^{\text {ta }}$ Inês & Cambé & SI & 30 & 30 & 0 & 1 \\
\hline $32^{\mathrm{b}}$ & $\mathrm{S}^{\text {ta }}$ Inês & $\begin{array}{l}\text { Joaquim } \\
\text { Távora }\end{array}$ & SI & 239 & 5 & 0 & 2 \\
\hline $38^{\mathrm{b}}$ & $\mathrm{S}^{\text {ta }}$ Inês & Londrina & SI & 120 & 21 & 0 & 5 \\
\hline 39 & $\mathrm{~S}^{\text {ta }}$ Inês & Porecatu & SI & 50 & 18 & 0 & 3 \\
\hline $41^{\mathrm{b}}$ & $\mathrm{S}^{\text {ta }}$ Inês & Londrina & SI & 70 & 10 & 0 & 3 \\
\hline $46^{\mathrm{b}}$ & $\mathrm{S}^{\text {ta }}$ Inês & Londrina & SI & 100 & 20 & 0 & 6 \\
\hline $50^{\mathrm{b}}$ & 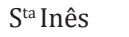 & Faxinal & I & 100 & 13 & 0 & 10 \\
\hline $53^{\mathrm{b}}$ & 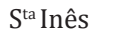 & Marilândia & SI & 50 & 10 & 0 & 2 \\
\hline 54 & S $^{\text {ta }}$ Inês & Marialva & $\mathrm{I}$ & 65 & 11 & 0 & 7 \\
\hline $7^{\mathrm{b}} 1$ & /2 S $\mathrm{S}^{\text {ta }}$ Inês & Ibiporã & SI & 108 & 9 & 7 & 3 \\
\hline 81 & /2 S $\mathrm{S}^{\mathrm{ta}}$ Inês & Porecatu & SI & 350 & 1,5 & 0 & 0 \\
\hline 101 & $/ 2 \mathrm{~S}^{\mathrm{ta}}$ Inês & $\begin{array}{c}\text { São } \\
\text { Jerônimo }\end{array}$ & SI & 64 & 11 & 0 & 0 \\
\hline 141 & /2 S $\mathrm{s}^{\mathrm{ta}}$ Inês & Londrina & SI & 25 & 8 & 0 & 2 \\
\hline 161 & /2 S $\mathrm{S}^{\mathrm{ta}}$ Inês & Assaí & SI & 40 & 15 & 0 & 3 \\
\hline $29^{\mathrm{b}} 1$ & $/ 2 \mathrm{~S}^{\text {ta }}$ Inês & Arapongas & SI & 250 & 2 & 0 & 3 \\
\hline 361 & $/ 2 \mathrm{~S}^{\mathrm{ta}}$ Inês & Mirador & $\mathrm{E}$ & 350 & 2,5 & 0 & 2 \\
\hline $37^{\mathrm{b}} 1$ & $/ 2 \mathrm{~S}^{\text {ta }}$ Inês & Florestópolis & SI & 100 & 5 & 0 & 0 \\
\hline $40^{\mathrm{b}} 1$ & $/ 2 \mathrm{~S}^{\mathrm{ta}}$ Inês & Maringá & SI & 200 & 4 & 0 & 5 \\
\hline 471 & $/ 2 \mathrm{~S}^{\mathrm{ta}}$ Inês & $\begin{array}{c}\text { Santa } \\
\text { Mariana }\end{array}$ & SI & 350 & 3 & 0 & 6 \\
\hline 2 & Lan & Cambé & SI & 200 & 4 & 7 & 3 \\
\hline $4^{b}$ & Lan & Rolândia & SI & 240 & 2 & 0 & 0 \\
\hline 11 & Lan & Ortigueira & $\mathrm{E}$ & 300 & 2 & 0 & 3 \\
\hline $12^{\mathrm{b}}$ & Lan & $\begin{array}{c}\text { Rio Branco } \\
\text { do Ivaí }\end{array}$ & SI & 180 & 5 & 0 & 10 \\
\hline 21 & Lan & Apucarana & SI & 180 & 17 & 0 & 0 \\
\hline $23^{\mathrm{b}}$ & Lan & Faxinal & $\mathrm{E}$ & 115 & 2 & 0 & 0 \\
\hline 33 & Lan & Londrina & $\mathrm{E}$ & 88 & 3 & 0 & 0 \\
\hline 35 & Lan & Rolândia & I & 102 & 3 & 0 & 0 \\
\hline 42 & Lan & Amaporã & $\mathrm{E}$ & 50 & 4 & 0 & 2 \\
\hline 52 & Lan & Faxinal & SI & 115 & 3 & 0 & 0 \\
\hline 55 & Lan & Sertanópolis & SI & 40 & 3 & 0 & 0 \\
\hline
\end{tabular}

a Identificação da propriedade. ${ }^{\mathrm{b}}$ Propriedade que tratava as matrizes acometidas. ${ }^{\mathrm{c}}$ Raça predominante: $S^{\text {ta }}$ Inês = Santa Inês; $1 / 2 S^{\text {ta }}$ Inês = mestiço Santa Inês; Lan= lanadas (raças com cobertura por lã). ${ }^{\mathrm{d}} \mathrm{SI}=$ Semi intensivo, $\mathrm{I}=$ Intensivo, E= Extensivo. ${ }^{\mathrm{e}}$ Informações referentes aos últimos 12 meses.

A época de maior ocorrência de mastite observada pelos produtores foi o início da lactação (69,2\%). Alguns observavam o problema no início da lactação e também após a separação dos cordeiros para o desmame $(17,9 \%)$. Poucos relataram a doença somente após o desmame dos cordeiros $(7,6 \%)$ ou em qualquer uma das fases da lactação $(5,3 \%)$. Apesar da descrição de casos de mastite em todas as fases da lactação, a maioria dos casos clínicos ocorre no início da lactação, coincidindo com o pico da produção leiteira, fato observado tanto em ovelhas de corte (Arsenault et al. 2008) como de leite (Menzies \& Ramanoon 2001). Oliveira (2007) também observou que a fase inicial da lactação é a de maior ocorrência da enfermidade $(80 \%$ dos casos ob- servados). No estudo de Guaraná et al. (2011), com fêmeas acometidas por mastite subclínica, 21,2 e $22,5 \%$ dos isolamentos bacterianos no leite ocorreram 10 dias antes do parto e até 15 dias após o parto, respectivamente.

Em $92 \%$ das propriedades onde ocorria mastite, foi relatada redução no ganho de peso dos cordeiros lactentes e em $70 \%$ relatou-se morte de cordeiros neonatos em decorrência da ausência ou diminuição da produção de leite da matriz. Cerca de 130 cordeiros neonatos, cujas mães tiveram mastite, morreram nos últimos 12 meses, anteriores à aplicação do questionário. Seis produtores não sabiam informar o número de neonatos mortos e dez produtores não relataram a morte de neonatos em decorrência da mastite. 
Quadro 2. Informações sobre o plantel, frequência da doença e manejo das propriedades $(n=15)$ onde a mastite não se apresentava como problema sanitário nas ovelhas de rebanhos de corte criados na região norte do Paraná

\begin{tabular}{|c|c|c|c|c|c|c|c|}
\hline ID $^{\text {a }}$ & Raça $^{\text {b }}$ & Município & $\begin{array}{l}\text { Tipo de } \\
\text { manejo }^{c}\end{array}$ & $\begin{array}{c}\text { Total } \\
\text { de ovelhas }\end{array}$ & $\begin{array}{c}\text { Frequência } \\
(\%)^{d}\end{array}$ & $\begin{array}{l}\text { Ovelhas } \\
\text { curadas }^{\mathrm{d}}\end{array}$ & $\begin{array}{c}\text { Ovelhas } \\
\text { descartadas }^{d}\end{array}$ \\
\hline 6 & $1 / 2 S^{\text {ta }}$ Inês & Bom Sucesso & SI & 200 & 0,5 & 0 & 0 \\
\hline 13 & $1 / 2 S^{\text {ta }}$ Inês & Cambé & SI & 80 & 1,25 & 0 & 0 \\
\hline 43 & $1 / 2 S^{\text {ta }}$ Inês & Ibiporã & $\mathrm{E}$ & 10 & 0 & - & - \\
\hline 49 & $1 / 2 S^{\text {ta }}$ Inês & Iguaraçu & SI & 80 & 0 & - & - \\
\hline 5 & Lan & Rolândia & SI & 80 & 0 & - & - \\
\hline 9 & Lan & Ortigueira & SI & 100 & 0 & - & - \\
\hline 15 & Lan & Bela Vista do Paraíso & SI & 80 & 0 & - & - \\
\hline 19 & Lan & Londrina & SI & 73 & 0 & - & - \\
\hline 22 & Lan & Porecatu & SI & 35 & 0 & - & - \\
\hline 27 & Lan & Rolândia & SI & 40 & 0 & - & - \\
\hline 34 & Lan & Pitanga & $\mathrm{E}$ & 200 & 0,5 & 0 & 0 \\
\hline 44 & Lan & São Jerônimo da Serra & SI & 200 & 0 & - & - \\
\hline 45 & Lan & Apucarana & $\mathrm{I}$ & 160 & 0,62 & 0 & 0 \\
\hline 48 & Lan & Jaguapitã & E & 80 & 0 & - & - \\
\hline 51 & Lan & anto Antônio da Platina & 1a SI & 73 & 0 & - & - \\
\hline
\end{tabular}

a Identificação da propriedade. ${ }^{\text {b }}$ Raça predominante: $1 / 2 \mathrm{~S}^{\text {ta }}$ Inês = mestiço Santa Inês; Lan= lanadas (raças

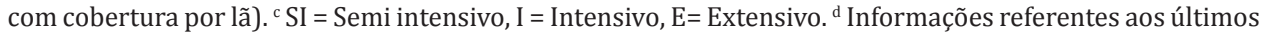
12 meses

Constatou-se correlação altamente significativa entre o número de cordeiros neonatos mortos e o número de ovelhas com mastite $(r=0,785 ; p<0,001)$. Veríssimo et al. (2010) relataram que a mastite foi apontada como a causa da morte de cordeiros lactentes em $70 \%$ dos casos numa estação de parição de ovelhas Santa Inês. Arsenault et al. (2008) verificaram que a presença de mastite clínica aumenta o risco de mortalidade de cordeiros em até cinco vezes num estudo realizado com ovelhas de corte no Canadá. No estudo de Nóbrega Júnior et al. (2005), a mastite clínica foi incriminada como a causa de mortalidade perinatal em cordeiros na Paraíba.

Em relação ao tratamento, nas propriedades onde ocorria a mastite, somente 22 proprietários $(56,4 \%)$ instituíam algum tipo de tratamento quando uma fêmea era acometida pela enfermidade. Em 13,7\% dessas propriedades só antimicrobianos intramamários eram utilizados, em 27,3\% somente antimicrobianos parenterais e em $59 \%$ a associação de antimicrobiano intramamário e parenteral era utilizada. De 329 ovelhas acometidas nos últimos 12 meses, 205 receberam algum tipo de tratamento, contudo, segundo os produtores, somente $4 \%$ destas matrizes se recuperaram e $2,4 \%$ morreram. As ovelhas restantes foram descartadas $(35,6 \%)$ ou mantidas no rebanho (58\%). Acredita-se que a baixa taxa de sucesso no tratamento pode ser atribuída ao caráter irreversível das lesões do parênquima mamário, na maioria dos casos, ou ao início tardio do tratamento. Além disso, a utilização dos antimicrobianos era inadequada, na maioria das vezes, com tempo de administração curto, em doses erradas e com troca frequente de princípios ativos. Mesmo Santos et al. (2007), após inoculação de S. aureus e tratamento precoce adequado, não conseguiram reestabelecer a função da glândula mamária acometida. Estes pesquisadores inocularam $S$. aureus na glândula mamária direita de 10 ovelhas primíparas da raça Santa Inês e realizaram o tratamento com três aplicações concomitantes parenterais e intramamárias de gentamicina associada a flunixina meglumina. Todos os animais desenvolveram quadros graves de mastite com sinais de envolvimento sistêmico. Após o tratamento, houve restabelecimento do apetite e melhora do quadro clínico geral, entretanto, não houve melhora da metade mamária inoculada, resultando em perda da função produtiva da glândula.

0 exame periódico da mama não era adotado em 59,2\% das propriedades estudadas. Somente em três propriedades esta prática era realizada nos momentos recomendados (na parição, na secagem e antes da estação de monta). Esta é uma medida diagnóstica importante para identificar casos novos ou crônicos, sendo essencial para diminuição da transmissão da doença e eliminação das fontes de infecção do rebanho (Contreras et al. 2007).

$\mathrm{Na}$ análise de fatores de risco para a mastite clínica, as variáveis associadas com a ocorrência desta condição nas ovelhas estudadas na análise univariada foram: sistema de criação $(p<0,001)$, raça $(p<0,001)$, frequência de limpeza de instalações $(p<0,001)$, época do desmame $(p<0,001)$, uso de antibiótico na secagem $(\mathrm{p}<0,001)$, confinamento de fêmeas na parição $(\mathrm{p}=0,199)$ e separação de fêmeas doentes $(\mathrm{p}=0,046)$ (Quadro 3). Na regressão logística foram identificados como fatores de risco: sistema de criação não extensivo e raça Santa Inês (Quadro 4).

Associação altamente significativa foi observada entre a raça Santa Inês e a ocorrência de mastite clínica $(p<0,001)$, sendo apontada como um fator de risco neste estudo $(0 \mathrm{R}=4,162)$. A maior frequência foi observada em fêmeas da raça Santa Inês $(13,3 \%)$, quando comparadas às ovelhas mestiças Santa Inês $(3,2 \%)$ e às de raças lanadas $(4,5 \%)$. Isso está de acordo com as observações de Veríssimo et al. (2003), comprovando que a ocorrência foi maior em fêmeas da raça Santa Inês do que nas ovelhas Ile de France e Suffolk. A maioria dos estudos nacionais sobre mastite clínica engloba rebanhos Santa Inês, relatando frequências 
Quadro 3. Análise univariada dos fatores de risco associados à mastite ovina em rebanhos de corte do norte do Paraná

\begin{tabular}{|c|c|c|c|c|c|}
\hline \multirow[t]{3}{*}{ Variáveis } & \multicolumn{4}{|c|}{ Mastite clínica } & \multirow[t]{3}{*}{$\mathrm{p}$} \\
\hline & \multicolumn{2}{|c|}{ Positivo } & \multicolumn{2}{|c|}{ Negativo } & \\
\hline & $\mathrm{N}$ & $\%$ & $\mathrm{~N}$ & $\%$ & \\
\hline \multicolumn{6}{|c|}{ Ovinocultura como principal atividade } \\
\hline Não & 152 & 6,6 & 2164 & 93,4 & 0,675 \\
\hline Sim & 177 & 6,9 & 2386 & 93,1 & \\
\hline \multicolumn{6}{|l|}{ Sistema de criação } \\
\hline Não extensivo & 310 & 7,8 & 3666 & 92,2 & $<0,001$ \\
\hline Extensivo & 19 & 2,1 & 884 & 97,9 & \\
\hline \multicolumn{6}{|l|}{ Raça } \\
\hline Santa Inês & 190 & 13,3 & 1242 & 86,7 & $<0,001$ \\
\hline Mestiço Santa Inês & 66 & 3,6 & 1771 & 96,4 & \\
\hline Lanadas & 73 & 4,5 & 1537 & 95,5 & \\
\hline \multicolumn{6}{|c|}{ Limpeza das instalações* } \\
\hline Diariamente & 88 & 5,7 & 1443 & 94,3 & $<0,001$ \\
\hline A cada 7 dias & 26 & 4,7 & 524 & 95,3 & \\
\hline A cada 15 dias & 85 & 12,9 & 575 & 87,1 & \\
\hline A cada 30 dias & 36 & 11,9 & 267 & 88,1 & \\
\hline Acima de 30 & 75 & 8 & 857 & 92 & \\
\hline \multicolumn{6}{|l|}{ Época do desmame } \\
\hline Até 90 dias & 244 & 6,5 & 3492 & 93,5 & $<0,001$ \\
\hline 91 a 120 dias & 68 & 12,6 & 470 & 87,4 & \\
\hline Após 120 dias & 17 & 2,8 & 588 & 97,2 & \\
\hline \multicolumn{6}{|l|}{$\begin{array}{l}\text { Uso de antibiótico } \\
\text { na secagem** }\end{array}$} \\
\hline Não & 275 & 8,2 & 3079 & 91,8 & $<0,001$ \\
\hline Sim & 37 & 4 & 883 & 96 & \\
\hline \multicolumn{6}{|l|}{$\begin{array}{l}\text { Confinamento de } \\
\text { fêmeas na parição* }\end{array}$} \\
\hline Não & 55 & 6,6 & 775 & 93,4 & 0,199 \\
\hline Sim & 257 & 8 & 2939 & 92 & \\
\hline \multicolumn{6}{|l|}{$\begin{array}{l}\text { Separação de } \\
\text { fêmeas doentes }\end{array}$} \\
\hline Não & 263 & 7,2 & 3406 & 92,8 & 0,046 \\
\hline Sim & 66 & 5,5 & 1144 & 94,5 & \\
\hline \multicolumn{6}{|l|}{$\begin{array}{l}\text { Descarte de fêmeas } \\
\text { acometidas }\end{array}$} \\
\hline Não & 148 & 6,5 & 2140 & 93,5 & 0,508 \\
\hline Sim & 181 & 7 & 2410 & 93 & \\
\hline
\end{tabular}

* Excluídas as fêmeas manejadas extensivamente. ** Excluídas as fêmeas submetidas ao método de desmame natural (acima de 120 dias).

Quadro 4. Análise multivariada dos fatores de risco associados à mastite ovina em rebanhos de corte do norte do Paraná

\begin{tabular}{|c|c|c|c|c|c|}
\hline Fatores de risco & Valor de $\mathrm{p}$ & OR & IC 95\% & Coeficiente & S.E. \\
\hline $\begin{array}{l}\text { Sistema de criação } \\
\text { não extensivo }\end{array}$ & $0<0,001$ & 2,869 & $1,465-5,617$ & 1,054 & 0,343 \\
\hline $\begin{array}{l}\text { Raça Santa Inês } \\
\text { Desmame após } \\
120 \text { dias }\end{array}$ & $\begin{array}{l}<0,001 \\
<0,001\end{array}$ & $\begin{array}{l}4,162 \\
0,738\end{array}$ & $\begin{array}{l}3,192-5,427 \\
0,376-1,452\end{array}$ & $\begin{array}{l}1,426 \\
-0,303\end{array}$ & $\begin{array}{l}0,135 \\
0,345\end{array}$ \\
\hline $\begin{array}{l}\text { Separação de fê- } \\
\text { meas doentes }\end{array}$ & 0,046 & 0,836 & $0,625-1,119$ & $-0,179$ & 0,149 \\
\hline
\end{tabular}

*Associação significativa ao nível de 5\%. OR = Odds ratio (Razão de chance), IC = intervalo de confiança de 95\%, S.E. = erro padrão de estimativa.

que variam de 5,9\% (Silva et al. 2010) a 24,5\% (Veríssimo et al 2010), o que reafirma que, de fato, a doença tem maior importância nessa raça. As fêmeas da raça Santa Inês apresentam período de lactação mais prolongado e produ- ção leiteira elevada (Sousa et al. 2005, Melo et al. 2008), características que podem favorecer a maior ocorrência de mastite. No único estudo brasileiro realizado com ovelhas leiteiras, fêmeas da raça Bergamácia submetidas a ordenha mecânica foram acompanhadas e não foram observados casos de mastite clínica, embora a frequência de mastite subclínica tenha sido 4,36\% (Bolsanello et al. 2009).

É descrito na literatura que a prática de manter os animais confinados, seja por um período do dia ou durante todo o tempo, aumenta a exposição das fêmeas a maior número de agentes causadores de mastite, devido ao acúmulo de matéria orgânica e umidade (Albenzio et al. 2002). Neste trabalho, sistema de criação não extensivo foi considerado um fator de risco para o desenvolvimento de mastite $(\mathrm{OR}=2,869)$. A limpeza irregular destas instalações é a principal característica que corrobora com este fato. $\mathrm{Na}$ análise univariada, foi observada uma associação significativa entre a limpeza das instalações e a ocorrência de mastite clínica $(\mathrm{p}<0,001)$. Somente em $22 \%$ das propriedades estudadas a limpeza das instalações era realizada diariamente e no restante a limpeza era feita a intervalos irregulares de tempo. 0 acúmulo de matéria orgânica no interior das instalações utilizadas para o pernoite das ovelhas foi observação muito comum no presente estudo. Acúmulo de matéria orgânica, aumento de umidade, de temperatura e sombreamento favorecem a multiplicação de agentes ambientais causadores de mastite (Winter 2001, Mota 2008). A prática de manter o rebanho preso nos apriscos durante a noite era adotada na maioria das propriedades como providência necessária para se evitar a predação. A superpopulação e o decúbito prolongado em locais com acúmulo de matéria orgânica podem expor as matrizes a novas infecções (Marogna et al. 2010).

A época em que o desmame é realizado foi associada com menor ocorrência de mastite. Embora a secagem tardia não tenha sido comprovada como fator de proteção nesse estudo (Quadro 4), ovelhas que permaneceram maior tempo em lactação tiveram menor probabilidade de desenvolver mastite clínica na lactação seguinte (Quadro 3). 0 desmame natural (após 120 dias de lactação) era uma prática mais frequentemente adotada nas propriedades sem mastite ( $40 \%$ delas), sendo realizado em apenas $10 \%$ daquelas com mastite. 0 restante das propriedades com incidência de mastite utilizava a separação súbita entre os cordeiros e as matrizes, no período de 30 a 119 dias de lactação. Em nenhuma delas se realizava o desmame gradual. 0 sistema de produção local visa ao abate do cordeiro precoce, o que inviabiliza o desmame natural em algumas propriedades. Entretanto, quando se objetiva a produção de cordeiros para abate a baixo custo, não há finalidade útil em antecipar o desmame quando as condições de manejo propiciam a engorda com suplementação ao pé da mãe. Nesse caso, o peso do cordeiro à terminação depende da produção de leite da ovelha e da disponibilidade e quantidade de alimentos sólidos oferecidos ao cordeiro (Almeida 2007). Santos (2008) relatou, em seu estudo, que a propriedade com maior frequência de mastite efetuava o desmame dos cordeiros aos 30 dias de lactação. 0 desmame precoce pode favorecer o desenvolvimento da doença nas 
ovelhas que produzem maior volume de leite porque a sua retenção no interior da glândula favorece a infecção. Nas ovelhas de raças lanadas, que possuem como característica a produção de menor volume de leite, o risco é naturalmente menor e a prática de desmame precoce parece não provocar impacto tão grande.

A utilização de antibioticoterapia na secagem foi associada com menor ocorrência de mastite clínica no presente estudo (Quadro 3). Esta medida ainda é de eficácia controversa em fêmeas ovinas (Bergonier \& Berthelot 2003). Alguns estudos demonstram que este procedimento pode favorecer o controle da mastite em ovelhas, prevenindo novas infecções na lactação seguinte e reduzindo a persistência de infecções anteriores (Coutinho et al. 2008, Linage \& Gonzalo 2008). Os resultados de Spanu et al. (2011) e de Pereira (2012) contrariam esse conceito, demonstrando que a terapia intramamária na secagem não influenciou a ocorrência de novas infecções da mama na parição. Alguns fatores podem comprometer a eficácia da terapia intramamária em ovelhas de corte na secagem, tais como: confinamento das matrizes no período puerperal, período seco longo e maior exposição aos agentes causadores em decorrência de limpeza inadequada das instalações. Outras investigações sobre o assunto são necessárias para sustentar que esse procedimento tenha, realmente, importância preventiva.

A separação de fêmeas doentes do restante do rebanho foi associada com menor ocorrência de mastite clínica no presente estudo, embora não tenha sido comprovada como fator de proteção (Quadro 4). A manutenção de fêmeas doentes junto às matrizes sadias contribui para o aumento do número de casos, pois os cordeiros possuem o hábito de mamar em outras ovelhas além da sua mãe. Desta maneira, agem como fômites, facilitando a propagação de agentes infecciosos, principalmente Staphylococcus spp. e Mannheimia haemolytica (Albenzio et al. 2002). Bergonier \& Berthelot (2003) recomendam a separação das fêmeas com mastite clínica do restante do rebanho. Apesar de não ter sido observada associação entre o descarte de fêmeas acometidas e a ocorrência de mastite, esta prática é uma das principais medidas adotadas em programas de controle da enfermidade, com o intuito de reduzir reservatórios de novas infecções (Bergonier et al. 2003, Anderson et al. 2004, Mota 2008). Bergonier \& Berthelot (2003) preconizam a eliminação de fêmeas com mastites agudas e crônicas graves, com envolvimento difuso do parênquima mamário e presença de abscessos.

Setenta ovelhas em lactação foram apresentadas pelos proprietários como portadoras de mastite, sendo 41 da raça Santa Inês, 19 mestiças Santa Inês e 10 de raças lanadas. Com o exame físico constatou-se que 53 ovelhas apresentavam mastite unilateral e 17 ovelhas apresentavam mastite bilateral, totalizando 87 mamas acometidas. A manifestação unilateral foi observada pela maioria dos produtores $(79,4 \%)$, fato também relatado por Oliveira (2007). Dentre as ovelhas acometidas 11 estavam na fase puerperal (até 48 horas pós-parto), 16 no terço inicial da lactação (primeiro mês pós-parto), 30 no terço médio da lactação (entre 30 e 60 dias pós-parto) e 13 no terço final da lactação (acima de 60 dias pós-parto).
Apesar da literatura internacional sobre mastite em ovelhas de leite ser numerosa, a maioria desses estudos priorizou as alterações celulares no leite, os achados microbiológicos e os métodos de prevenção (Menzies \& Ramanoon 2001, Pengov 2001, Winter 2001, Bergonier et al. 2003, Bergonier \& Berthelot 2003, Chaffer et al. 2003, Berthelot et al. 2006, Contreras et al. 2007, Linage \& Gonzalo 2008). Ao contrário do que se observa no caso das vacas, há poucos relatos que caracterizam as manifestações exibidas pelas ovelhas quando apresentam mastite clínica (Anderson, Hull \& Pugh 2004, Marogna et al. 2010). Com exceção dos estudos de Blagitz (2007) e de Santos et al. (2007), não há informações que caracterizam os detalhes sobre a evolução e os sinais exibidos por ovelhas de corte acometidas pela doença.

Com o intuito de apresentar a caracterização clínica mais detalhada possível, decidiu-se adotar a chave de classificação preconizada por Grunert (1993) para a mastite bovina. Vinte e sete metades mamárias (31\%) apresentavam mastite aguda, quase todas classificadas como mastites flegmonosas (Quadro 5). Estas mamas apresentavam endurecimento difuso do parênquima com edema, aumento de temperatura local, dor à palpação e ausência de secreção láctea ou substituição do leite por sangue ou soro, na maioria dos casos. Todos os casos apresentaram evolução muito rápida e aconteceram no período puerperal ou no início da lactação. Somente um caso de mastite aguda gangrenosa foi observado, com coloração arroxeada da pele do úbere, diminuição de temperatura local, endurecimento difuso do parênquima e desprendimento de uma pequena área de pele. Esta matriz era a única que apresentava sinais de envolvimento sistêmico, como apatia, anorexia, isolamento do rebanho e hipertermia $\left(40,5^{\circ} \mathrm{C}\right)$. A secreção láctea se apresentava serosanguinolenta e com o cultivo microbiológico isolou-se Mannheimia haemolytica.

Em 60 metades mamárias (69\%) observou-se a forma crônica da enfermidade: 18 casos classificados como mastite abscedante, 11 casos como mastite catarral e 31 como mastite flegmonosa (Quadro 5). As mamas classificadas como abscedantes ou catarrais apresentavam histórico de presença de alterações na glândula acompanhadas por modificações na secreção láctea ou diminuição da produção de leite há pelo menos uma lactação, ou seja, esses processos não se iniciaram na lactação atual. As mastites abscedantes caracterizaram-se pela presença de abscessos no parênquima mamário com tamanhos variados, usualmente em número maior do que um e raramente fistulados para o exterior. Em 55,5\% das mamas afetadas por abscessos não havia mais secreção de leite e somente pús era eliminado pelo canal do teto. Nas mastites classificadas como catarrais as nodulações do parênquima mamário eram a característica marcante e metade das mamas eliminava leite contendo grumos.

Nas mamas acometidas pela mastite flegmonosa crônica observou-se parte ou todo o parênquima mamário endurecido, porém sem o edema e os sinais característicos das reações inflamatórias agudas. Doze mamas haviam sido acometidas na lactação anterior e produziam leite, com aspecto normal, porém em pequena quantidade. 0 restante 


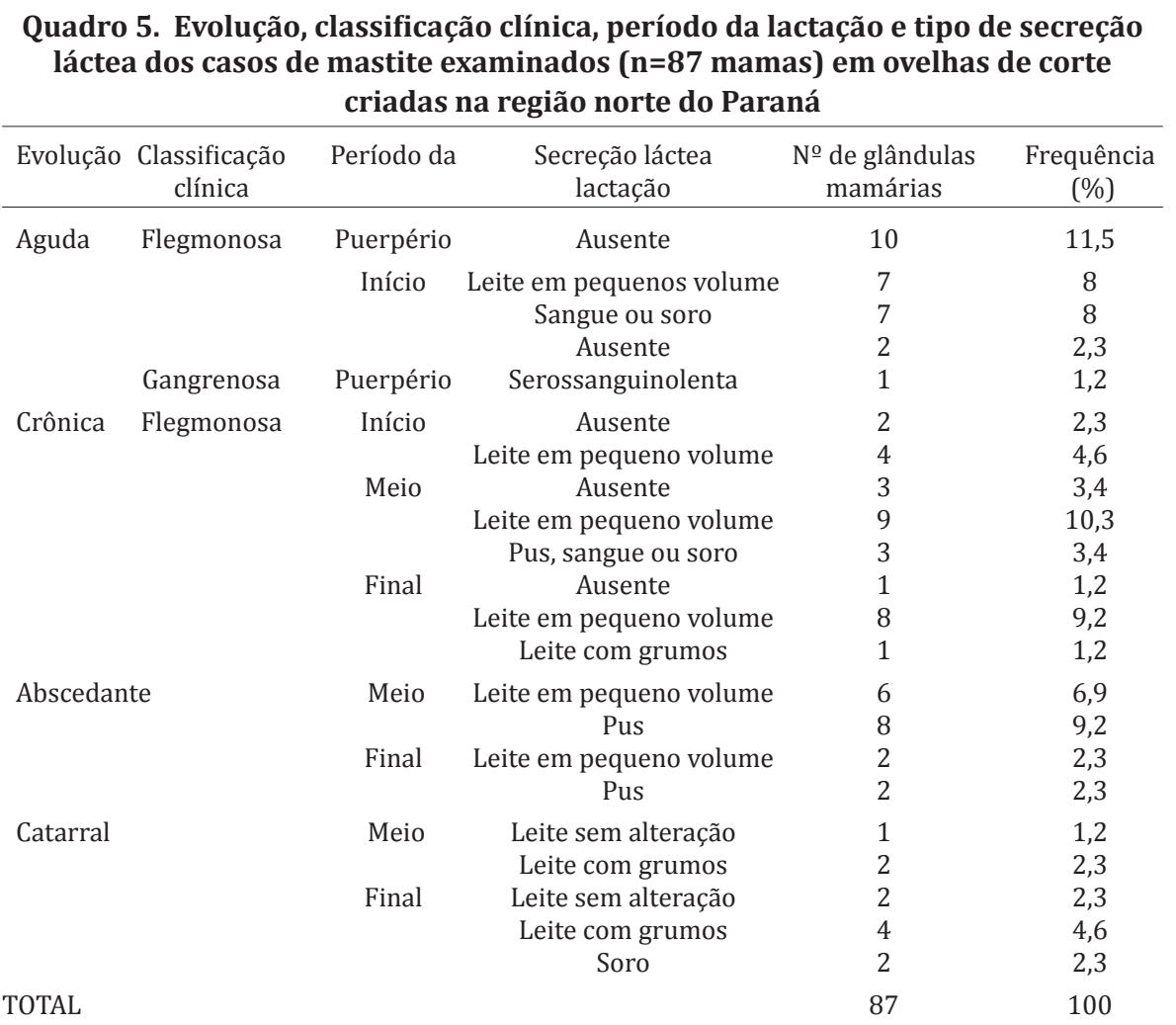

das mamas acometidas $(\mathrm{n}=19)$ havia apresentado o quadro agudo no início da lactação atual. 0 maior número de processos crônicos observados nas ovelhas examinadas deveu-se principalmente ao fato de os produtores não possuírem o hábito de descartar as ovelhas acometidas pela doença, mantendo-as no rebanho desde que ainda tivessem uma metade mamária funcional.

As alterações detectadas com o exame físico da mama foram condizentes com as manifestações clínicas relatadas anteriormente pelos produtores. 0 endurecimento difuso do parênquima mamário foi o único sinal clínico apontado por todos os 39 produtores. Em seguida, o aumento da temperatura local e as alterações da secreção láctea foram apontados por 24 produtores. A ausência da produção de leite, a dor à palpação, a vermelhidão, a diminuição da produção de leite e o aumento de volume da mama foram relatados por 21,18 , oito, oito e quatro produtores, respectivamente. Os sinais relatados estão de acordo com os citados na literatura (Jones \& Watkins 2000, Anderson et al. 2004, Blagitz 2007, Santos et al. 2007, Santos 2008).

É necessário destacar a predominância de casos de mastite flegmonosa nas ovelhas do presente estudo. Nas vacas, ao contrário das ovelhas, a mastite catarral ocorre predominantemente e a flegmonosa é incomum e provoca sinais sistêmicos (Grunert 1993). Entretanto, essa forma de mastite ocorre na mesma fase da lactação (puerpério e início) e tem evolução rápida em ambas as espécies. Este tipo de mastite geralmente não responde ao tratamento com antibióticos e a glândula acometida frequentemente apresenta perda, total ou parcial, da sua função, fato confirmado também pelos produtores que participaram dessa pesquisa.
O exame microbiológico do leite ou da secreção recuperada por ordenha foi realizado nas 69 amostras obtidas, das quais 22 foram negativas, 44 foram positivas e em três amostras houve contaminação. 0 agente etiológico mais prevalente neste estudo foi Staphylococcus coagulase negativo (SCN), isolado em 24 amostras (54,5\%). Em seguida foram isolados Staphylococcus aureus e Arcanobacterium pyogenes, em cinco amostras cada $(11,4 \%)$. Micrococcus spp. foi isolado em três amostras (7\%) e Manheimmia haemolytica, Escherichia coli e Streptococcus esculina positivo foram isolados em duas amostras cada um (4,5\%). Streptococcus esculina negativo foi isolado em uma única amostra $(2,2 \%)$. Os estreptococos, Micrococcus spp. e A. pyogenes foram isolados exclusivamente dos casos crônicos de mastite, enquanto $M$. haemolytica e $E$. coli somente dos casos agudos.

Os estafilococos são os agentes mais prevalentes nas infecções intramamárias em ovinos (Bergonier et al. 2003, Contreras et al. 2007), inclusive nos levantamentos realizados no Brasil (Peixoto, Mota \& Costa 2010). A grande maioria dos estudos aponta $S$. aureus como principal agente de mastite clínica e SCN como os principais agentes de mastite subclínica (Menzies \& Ramanoon 2001, Bergonier \& Berthelot 2003, Bergonier et al. 2003). Entretanto, alguns autores já ressaltaram que SCN podem ser importantes agentes de mastite clínica (Pengov 2001, Contreras et al. 2007), concordando com os achados deste trabalho. $\mathrm{Na}$ pesquisa de Santos (2008), SCN foram os responsáveis por $64,8 \%$ dos casos de mastite clínica e $S$. aureus por 21,42\% dos casos. Também houve predominância de isolamento de SCN em amostras provenientes de mastite clínica no estudo de Silva et al. (2010), no qual 42,9\% dos isolados eram SCN 
e somente $9,52 \%$ eram $S$. aureus. No trabalho de Oliveira (2007), S. aureus foi isolado em sete e SCN em seis das 18 amostras de leite colhidas de matrizes com mastite clínica. $S$. aureus é um agente contagioso, sendo muito prevalente em rebanhos ovinos de leite, nos quais as matrizes são ordenhadas diariamente (Bergonier \& Berthelot 2003). Ao contrário das ovelhas produtoras de leite, as fêmeas estudadas possuem aptidão para a produção de carne e não são submetidas à ordenha, o que pode explicar o predomínio dos SCN, agentes ambientais, nos casos clínicos de mastite.

Segundo Arsenault et al. (2008) e Omaleki et al. (2011), $M$. haemolytica é tão importante quanto $S$. aureus como agente etiológico de mastite clínica em ovelhas de corte. Nestes rebanhos, a saliva e as secreções respiratórias dos cordeiros são consideradas as principais vias de eliminação do agente, com posterior contaminação do úbere da ovelha (Menzies \& Ramanoon 2001, Mota 2008). Todavia, o isolamento de M. haemolytica em amostras de leite de ovinos de corte é incomum no Brasil. Santos (2008) relatou o primeiro isolamento de $M$. haemolytica em uma das 78 amostras de leite coletadas de ovelhas Santa Inês com mastite clínica na Paraíba. 0 presente estudo relata pela segunda vez o isolamento deste agente no Brasil, ocorrendo em duas amostras de secreção láctea. Uma era proveniente do único caso de mastite gangrenosa observado (Quadro 5). A outra foi obtida em um caso de mastite aguda classificada como flegmonosa, com endurecimento difuso do parênquima e secreção com aspecto de soro lácteo. As duas ovelhas eram da raça Santa Inês, pertenciam a rebanhos diferentes e desenvolveram a doença na fase inicial da lactação (1 dia e 7 dias de lactação).

Em 18 casos de mastite flegmonosa (oito agudos e 10 crônicos) e em dois casos de mastite catarral crônica, as amostras de secreção láctea foram semeadas em meio específico para Mycoplasma spp., porém todas foram negativas. Apesar de alguns casos presentes neste estudo se assemelharem com os de agalactia contagiosa, é importante ressaltar que nenhum dos animais examinados apresentou febre, poliartire, conjuntivite ou sinais respiratórios concomitantes à mastite. Não foram observados surtos de mastite ou animais de outras faixas etárias com esses sinais, conforme descrito em relatos desta doença na literatura (Azevedo et al. 2006, Corrales et al. 2007). Nesse estudo, a única ovelha que exibiu sinais sistêmicos, como febre e depressão, foi a que apresentava mastite grangrenosa por M. haemolytica.

A mastite em ovelhas de corte representa, portanto, um problema sanitário relevante nos rebanhos explorados na região norte do Paraná. Este trabalho, ao classificar as manifestações clínicas, relatou o predomínio da mastite flegmonosa. Esta forma é de instalação rápida e aguda, no início da lactação, com envolvimento difuso do parênquima mamário, ausência de produção de leite e reduzida probabilidade de sucesso terapêutico. 0 agente etiológico mais prevalente foi SCN, reafirmando sua importância como causador de mastite clínica em ovelhas de corte. É importante ressaltar o isolamento de M. haemolytica de dois casos acompanhados. 0 presente estudo levantou, ainda, alguns fatores de risco para a ocorrência da enfermidade, como a raça Santa Inês, ovelhas sabidamente maiores produtoras de leite do que as fêmeas de raças lanadas, e a criação de animais em sistema não extensivo. 0 confinamento dos ovinos em apriscos durante a noite é uma prática adotada na região estudada como forma de evitar a predação. Desse modo, é necessário que a limpeza adequada das instalações seja realizada com frequência, o que não foi observado na maioria das propriedades visitadas. A adoção do desmame tardio, após 120 dias de lactação, pode ser uma medida interessante para a prevenção da mastite, principalmente em rebanhos Santa Inês, cujas fêmeas possuem período maior de lactação. Acredita-se que este pode ser um ponto chave para a prevenção da mastite nos rebanhos ovinos no estado do Paraná, assim como a conscientização dos produtores sobre a necessidade da limpeza diária das instalações.

Agradecimentos.- À Cooperativa Coopercapanna ${ }^{\circledR}$, por fornecer o contato dos produtores, e à Coordenação de Aperfeiçoamento de Pessoal de Nível Superior (CAPES), pela concessão da bolsa de mestrado.

\section{REFERÊNCIAS}

Albenzio A., Taibi L., Muscio A. \& Sevi A. 2002. Prevalence and etiology of subclinical mastitis in intensively managed flocks and related changes in the yield and quality of ewe milk. Small Rumin. Res. 43(3):219-226.

Almeida B.M. 2007. Aspectos da sustentabilidade da ovinocultura e avaliação de uma metodologia profilática contra a mastite clínica em ovelhas Santa Inês no agreste sergipano. Dissertação de Mestrado em Agroecossistemas, Núcleo de Pesquisa e Pós Graduação e Estudo em Recursos Naturais, Universidade Federal de Sergipe, São Cristóvão, SE. 71p.

Anderson D.E., Hull B.L. \& Pugh D.G. 2004. Enfermidades da glândula mamária, p.389-395. In: Pugh D.G. (Ed.), Clínica de Ovinos e Caprinos. Roca, São Paulo.

Arsenault J., Dubreuil P., Higgins R. \& Bélanger D. 2008. Risk factors and impacts of clinical and subclinical mastitis in commercial meat-producing sheep flocks in Quebec, Canada. Prev. Vet. Med. 87(4):373-393.

Azevedo E.O., Alcântara M.D.B., Nascimento E.R., Tabosa I.M., Almeida J.F., Araújo M.D., Rodrigues A.R.O., Riet-Correa F. \& Castro R.S. 2006. Contagious agalactia by Mycoplasma agalactiae in small ruminantes inBrazil: first report. Braz. J. Microbiol. 37:576-581.

Bergonier D. \& Berthelot X. 2003. New advances in epizootology and control of ewe mastitis. Livest. Prod. Sci. 79(1):1-16.

Bergonier D., Crémoux R., Rupp R., Lagriffoul G. \& Berthelot X. 2003. Mastitis of dairy small ruminants. Vet. Res. 34:689-716.

Berthelot X., Lagriffoul G., Concordet D., Barillet F. \& Bergonier D. 2006. Physiological and pathological threshold of somatic cell count in ewe milk. Small Rumin. Res. 62(1):27-31.

Blagitz M.G. 2007. Avaliação da relação do exame físico da glândula mamária de ovelhas da raça Santa Inês com o perfil citológico e bacteriológico do leite. Dissertação de Mestrado em Medicina Veterinária, Departamento de Clínicas Veterinárias, Universidade de São Paulo, São Paulo, SP. 195p.

Blagitz M.G., Batista C.F., Souza F.N., Benites N.R., Melville P.A., Stricagnolo C.R., Ricciardi M., Gomes V., Azedo M.R., Sanches B.G.S. \& Della Libera A.M.M.P. 2008. Perfil celular e microbiológico do leite de ovelhas Santa Inês no período lactante e pós desmame. Pesq. Vet. Bras. 26(9):417-422.

Bolsanello R.X., Hartmen M., Domingues P.F., Júnior A.S.M. \& Langoni H. 2009. Etiologia da mastite em ovelhas Bergamácia submetidas a ordenha mecânica, criadas em propriedade de Botucatu, SP. Vet. Zootec. 16(1):221-227.

Brasil 2010. Produção Pecuária Municipal 2010. Instituto Brasileiro de Geografia e Estatística. Disponível em <http://www.ibge.gov.br/home/estatistica/economia/ppm/2010/ppm2010.pdf> Acesso em 12 jan. 2012.

Carter G.R. \& Cole Junior J.R. 1990. Diagnostic Procedures in Veterinary Bacteriology and Mycology. $5^{\text {th }}$ ed. Academic Press, New York. 620p. 
Chaffer M., Leitner G., Zamir S., Winkler M., Glickman A., Ziv N. \& Saran A. 2003. Efficacy of the dry-off treatment in sheep. Small Rumin. Res. 47(1):11-16.

Contreras A., Sierra D., Sánchez A., Corrales J.C., Marco J.C., Paape M.J. \& Gonzalo C. 2007. Mastitis in small ruminant. Small Rumin. Res. 68(2):145-153.

Coutinho D.A., Costa J.N., Ribeiro M.G. \& Torres J.A. 2006. Etiologia e sensibilidade antimicrobiana in vitro de bactérias isoladas de ovelhas da raça Santa Inês com mastite subclínica. Revta Bras. Saúde Prod. Anim. 7(2):139-151.

Coutinho D.A., Costa J.N., Ribeiro M.G. \& Salerno T. 2008. Eficácia do cefalônio anidro intramamário na secagem de ovelhas Santa Inês. Vet. Zootec. 15(3):469-477.

Corrales J.C., Esnal A., De la Fe C., Sanchéz A., Assunçao P., Poveda J.B. \& Contreras A. 2007. Contagious agalactia em small ruminants. Small Rumin. Res. 68:154-166.

Domingues P.F., Lucheis S.B., Serrão L.S., Fernandes S., Contente A.P.A., Martins E.C.V. \& Langoni H. 2006. Etiologia e sensibilidade bacteriana da mastite subclínica em ovelhas da raça Santa Inês. Ars Vet. 22(2):146152.

Grunert E. 1993. Sistema genital feminino, p.269-314. In: Dirksen G., Gründer H.D. \& Stöber M. (Eds), Rosenberger: Exame Clínico dos Bovinos. Guanabara Koogan, Rio de Janeiro.

Guaraná E.L.S., Santos R.A., Campos A.G.S.S., Silva N.S., Afonso J.A.B. \& Mendonça C.L. 2011. Dinâmica celular e microbiológica do leite de ovelhas Santa Inês acompanhadas durante a lactação. Pesq. Vet. Bras. 31(10):851-858.

Hosmer D.W. \& Lemeshow S. 2000. Applied logistic regression. John Wiley and Sons, New York. 375p.

Jones J.E.T. \& Watkins G.H. 2000. Mastitis and contagious agalactia, p.7580. In: Martin W.B. \& Aitken I.D. (Eds), Diseases of Sheep. $3^{\text {rd }}$ ed. Blackwell Science, UK.

Linage B. \& Gonzalo C. 2008. Influence of an intramammary infusion at drying-off of combined penethamate hydriodidr, benethmine penicillin, and framycetin sulfate on intramammary infections and somatic cell counts in dairy sheep. J. Dairy Sci. 91(9):3459-3466.

Marogna G., Rolesu S., Lollai S., Tola S. \& Leori G. 2010. Clinical findings in sheep farms affected by recurrent bacterial mastitis. Small Rumin. Res. 88(2):119-125.

Melo C., Almeida B.M., Oliveira A.A., Azevedo H.C., Melo I.S.S. \& Mata S.S. 2008. Avaliação de uma metodologia profilática contra mastite subclínica em ovelhas da raça Santa Inês. Arq. Bras. Med. Vet. Zootec. 60(4):1011-1013.

Mendonça C.L., Afonso J.A.B. \& Costa N.A. 2005. Mastite em ovelhas. Vet. Zootec. CRMV-PE 25:10-13.

Menzies P.I. \& Ramanoon S. 2001. Mastitis of sheep and goats. Vet. Clin. North Am., Food Anim. Pract. 17(2):333-358.

Mota R.M. 2008. Aspectos epidemiológicos, diagnóstico e controle das mastites em caprinos e ovinos. Tecnol. Ciênc. Agropec. 2(3):57-61.

National Mastitis Council 2004. Microbiological Procedures for the Diagnosis of Bovine Udder Infection and Determination of Milk Quality. $4^{\text {th }}$ ed. National Mastitis Council, Verona.

Nóbrega Júnior J.E., Riet-Correa F., Nóbrega R.S., Medeiros J.M., Vasconcelos J.S., Simões S.V.D. \& Tabosa I.M. 2005. Mortalidade perinatal de cordeiros no semi-árido da Paraíba. Pesq. Vet. Bras. 25(3):171-178.

Nunes G.R., Blagitz M.G., Freitas C.B., Souza F.N., Ricciardi M., Stricagnolo C.R., Sanches B.C.G., Azedo M.R., Sucupira M.C.A. \& Della Libera A.M.M.P.
2008. Avaliação de indicadores inflamatórios no diagnóstico da mamite ovina. Arqs Inst. Biológico, São Paulo, 75(3):271-278.

Oliveira V.L.M. 2006. Aspectos do leite e mastite em ovinos da raça Santa Inês em Sergipe. Dissertação de Mestrado em Agroecossistemas, Núcleo de Pesquisa e Pós-Graduação e Estudo em Recursos Naturais, Universidade Federal de Sergipe, São Cristóvão, SE. 70p.

Oliveira L.G. 2007. Estudo clinico-epidemiológico e bacteriológico da mastite em ovelhas da raça Santa Inês no agreste meridional do Estado do Pernambuco. Dissertação de Mestrado em Ciência Veterinária, Universidade Federal Rural do Pernambuco, Recife, PE. 50p.

Omaleki L., Browning G.F., Allen J.L. \& Barber S.R. 2011. The role of Mannheimia species in ovine mastitis. Vet. Microbiol. 153(1):67-72.

Paraná 2008. Ovinos: número de cabeças abatidas e produção de carne por unidade administrativa da SEAB: 2003-2007. Secretaria de Agricultura e Abastecimento (SEAB). Disponível em <http://www. seab.pr.gov/ arquivos/File/deral/pec.5> Acesso em 6 mai. 2010.

Peixoto R.M., Mota R.A. \& Costa M.M. 2010. Mastite em pequenos ruminantes no Brasil. Pesq. Vet. Bras. 30(9):754-762.

Pengov A. 2001. The role of CNS and associated SCC in the ovine mammary gland. J. Dairy Sci. 84(3):572-574.

Pereira P.F.V. 2012. Saúde da glândula mamária de ovelhas da raça Santa Inês na secagem e no puerpério e avaliação da terapia intramamária com gentamicina na secagem. Dissertação de Mestrado em Ciência Animal, Universidade Estadual de Londrina, Londrina, PR. 67p.

Pretto L.G., Müller E.E., Freitas J.C., Mettifogo E., Buzinhani M., Yamaguti M. \& Salvador R. 2001. Mastite bovina por Mycoplasma bovis em rebanhos leiteiros. Pesq. Vet. Bras. 21(4):143-145.

Quinn P.J., Carter M.E., Markey B. \& Carter G.R. 1994. Clinical Veterinary Microbiology. Wolf, London. 648p.

Santos R.A., Mendonça C.L., Afonso J.A.B. \& Simão L.C.V. 2007. Aspectos clínicos e características do leite em ovelhas com mastite induzida experimentalmente com Staphylococcus aureus. Pesq. Vet. Bras. 27(1): 6-12.

Santos H.C. 2008. Mastite clínica em ovelhas da raça Santa Inês no semi-árido da Paraíba. Dissertação de Mestrado em Medicina Veterinária: Ruminantes e Equídeos, Universidade Federal de Campina Grande, Patos, PB. 36p.

Silva N.S., Silveira J.A.S., Pinheiro C.P., Sousa M.G.S., Oliveira C.M., Mendonça C.L., Duarte M.D. \& Barbosa J.D. 2010. Etiologia e perfil de sensibilidade de bactérias isoladas de ovelhas com mastite na região nordeste do estado do Pará. Pesq. Vet. Bras. 30(12):1043:1048.

Sousa W.H., Lobo R.N.B. \& Morais R.M. 2005. Santa Inês: estado da arte e perspectivas. O Berro 82:78-82.

Spanu C., Berger Y.M., Thomas D.L. \& Ruegg P.L. 2011. Impact of intramammary antimicrobial dry treatment and teat sanitation on somatic cell count and intramammary infection in dairy ewes. Small Rumin. Res. 97:139-145

Veríssimo C.J., Baldassi L., Hellmeister Z.M.M., Cortez D.H., Kozuki F.T., Otuki A.K. \& Binuesa F. 2003. Prevalência e prejuízos da mastite em um rebanho ovino. Anais $30^{\circ}$ Congresso Brasileiro de Medicina Veterinária, Manaus, AM, p.4.

Veríssimo C.J., Zafalon L.F., Otsuk L.P. \& Nassar A.F.C. 2010. Prejuízos causados pela mastite em ovelhas Santa Inês. Arqs Inst. Biológico, São Paulo, 77(4):583-591.

Winter A. 2001. Mastitis in ewes. In Practice 23(3):160-163.

Zar J.H. 1999. Biostatistical Analysis. $4^{\text {th }}$ ed. Prentice Hall, Upper Saddle River. 